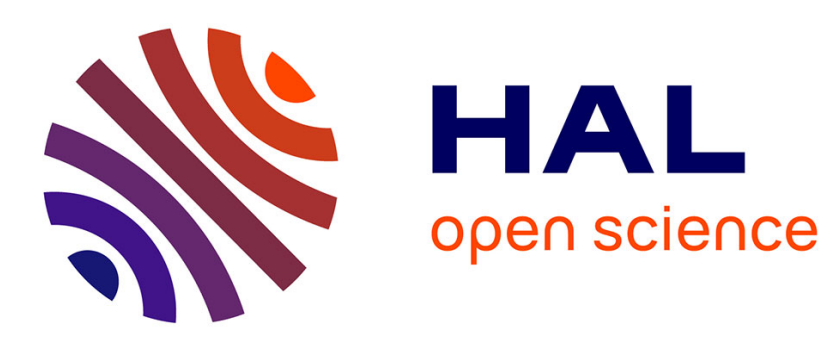

\title{
Stress intensity factors and fatigue growth of a surface crack in a drill pipe during rotary drilling operation
}

\author{
Ngoc Ha Dao, Hedi Sellami
}

\section{To cite this version:}

Ngoc Ha Dao, Hedi Sellami. Stress intensity factors and fatigue growth of a surface crack in a drill pipe during rotary drilling operation. Engineering Fracture Mechanics, 2012, 96, pp.626-640. 10.1016/j.engfracmech.2012.09.025 . hal-00773612v4

\section{HAL Id: hal-00773612}

\section{https://hal-mines-paristech.archives-ouvertes.fr/hal-00773612v4}

Submitted on 25 Oct 2013

HAL is a multi-disciplinary open access archive for the deposit and dissemination of scientific research documents, whether they are published or not. The documents may come from teaching and research institutions in France or abroad, or from public or private research centers.
L'archive ouverte pluridisciplinaire HAL, est destinée au dépôt et à la diffusion de documents scientifiques de niveau recherche, publiés ou non, émanant des établissements d'enseignement et de recherche français ou étrangers, des laboratoires publics ou privés. 


\title{
Stress intensity factors and fatigue growth of a surface crack in a drill pipe during rotary drilling operation
}

\author{
Ngoc Ha Dao ${ }^{\mathrm{a}, *}$, Hedi Sellami ${ }^{\mathrm{a}}$ \\ ${ }^{a}$ Mines ParisTech, 35 rue Saint-Honoré, 77305 Fontainebleau cedex, France
}

\begin{abstract}
Drill pipe in a curved section of the drilled well is considered as a rotating hollow cylinder subjected to bending and tension loads. So in this paper, the stress intensity factors and the fatigue growth of a circumferential semi-elliptical surface crack in a hollow cylinder subjected to rotary bending and tension are studied. A stress intensity factor database for three loading cases is build for numerous configurations using 3D Finite Element Models. The crack propagation model employs the Walker fatigue growth rate law. Using this model, we can study the evolution of parameters characterizing the process of crack propagation.
\end{abstract}

Keywords: Fatigue, Crack growth, Stress intensity factor, Circumferential semi-elliptical surface crack, Hollow cylinder, FEM, Drill pipe, Damage

\section{Introduction}

It is well known that drill pipe fatigue in oil-gas drilling operations represents more than $30 \%$ of the drill pipe damage. The recent development of drilling techniques allowed wells with more and more complex trajectory to be drilled: horizontal well, extended-reach well, deep well in very aggressive environments. The complex trajectory of the wells induces a high mechanical stress in the drill string, which contributes to the severity of drill pipe fatigue. The rotation of drill pipe in a curved section of well in which there is a change of hole angle and/or hole direction, commonly called "dog-leg", creates a rotary bending moment and produces the cyclic bending loading in the drill pipe. This is the main cause of drill pipe fatigue during the drilling operation.

In this paper, the fatigue growth of a circumferential semi-elliptical surface crack of a rotating hollow cylinder subjected to bending moment and tension is studied. The semi-elliptical crack is characterized by two parameters: the relative crack depth $A / T$ (crack depth/cylinder thickness) and the ellipse aspect ratio $B / A$ (ratio of the two ellipse radii). The ellipse center is assumed to be on the cylinder external surface (Figs. 1a and 1b). 3D finite element simulations of the cracked structure were carried out using the CASTEM code (developed by the Commissariat à l'Energie Atomique, France). These simulations allow the stress intensity factors (SIFs) along the crack front to be determined. A large number of simulations use various values of the ratio of $R_{\text {int }} / T$ (internal radius/thickness of cylinder) from 1 to 10 , $A / T$ from 0.05 to 0.95 and $B / A$ from 0.75 to 20 . This allows us to build a SIF database for three loading cases: bending moments $\left(M_{x 1}\right.$ about $O_{x 1}$ axis and $M_{y 1}$ about $O_{y 1}$ axis) and tension ( $\left.T_{e}\right)$ (Fig. 2).

Due to the stress and strain singularity at the intersection points of the crack front with the cylinder external surface, the assumptions of the linear elastic fracture mechanics (LEFM) is not valid at these points. However, this discontinuity is limited to a very small region around the points on the cylinder surface, and the stress intensity factor can be calculated using an asymptotic approach: that is, the SIF at the point on the cylinder external surface can be calculated from the results related to the nearest node in the structure.

\footnotetext{
*Corresponding author. Tel.: +331646949 07; fax: +33164694951

Email addresses: ngoc-ha.dao@mines-paristech.fr (Ngoc Ha Dao), hedi.sellami@mines-paristech.fr (Hedi Sellami)
} 


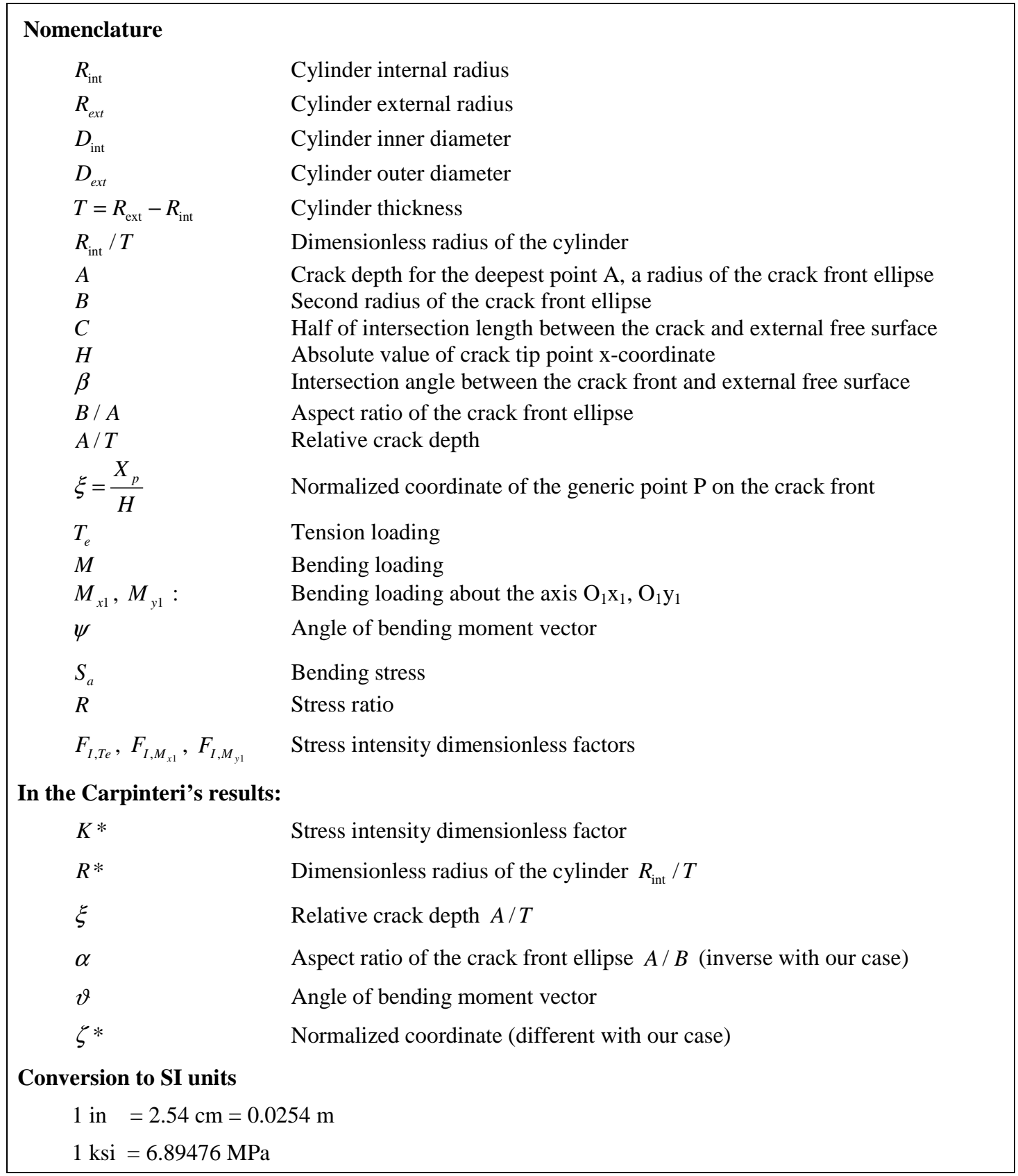

The semi-elliptical crack shape is the most used to study a hollow cylinder surface crack. Lin and Smith [1], using a 3D finite element model, showed that all the defects of any initial shape get semi-elliptical shape after some cycles of loading in a process of fatigue crack propagation. The simulations used a two-parameter theoretical model (the center of the crack ellipse is fixed on the cylinder external surface). Carpinteri and Brighenti [2] used a three-parameter theoretical model of semi-elliptical crack (where the crack ellipse center moves along the cylinder diameter) to analyze the fatigue crack propagation in a pipe subjected to cyclic bending. Their results showed that the ellipse crack center is rapidly approaching the surface. Therefore, a three-parameter model is not needed and a two-parameter model is quite enough to describe the process.

Carpinteri et al. have published a list of papers $[2,3,4,5]$ on crack propagation in a pipe for several cases: cyclic tension, cyclic bending moment and rotary bending moment. In the case of rotary bending moment, they have given the results for a thick pipe $\left(R_{\text {int }} / T=1\right)$. Furthermore, the influence of the combination of the rotary bending moment and the tension on the crack propagation has not been studied.

In the present paper, we will present the solutions for a more general problem. A program was written 


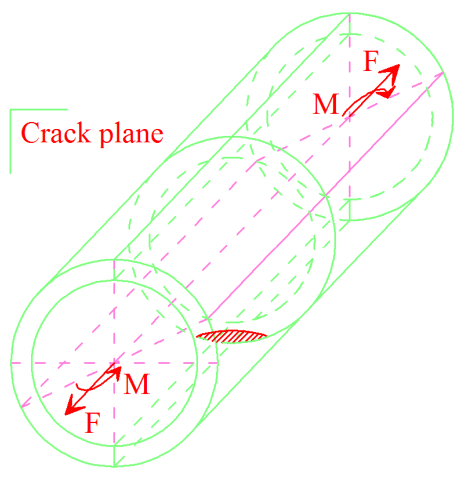

(a) Cracked cylinder and loading

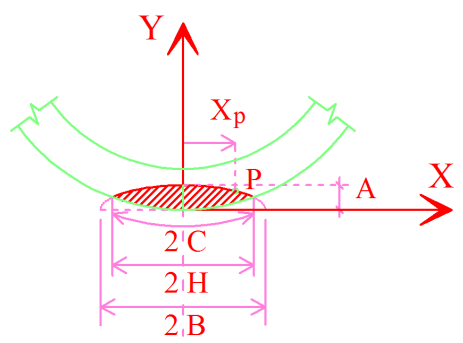

(b) Crack geometry and parameters

Figure 1

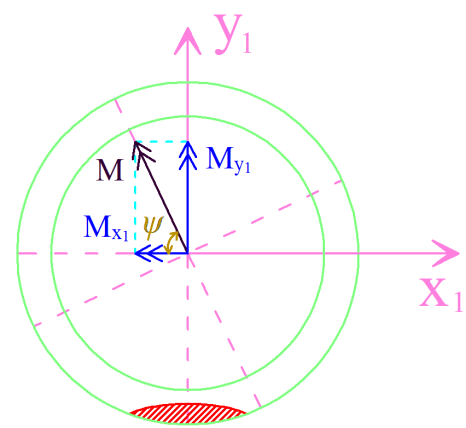

Crack plan

Figure 2: Decomposition of the bending moment

to determine the crack propagation when the geometries of the cylinder and the initial crack are known as well as the loadings. This model is very easy to adjust the input parameters to study different cases. Furthermore, the model allows all parameters during the crack propagation (crack geometry, SIFs, changes of parameters after a computation step) to be exported. Crack propagation is determined considering the following points:

- The problem is studied using the Walker law (it is identical to the Paris law in the "pulsating tension" case $R=0$ ). The coefficients of Paris law for commercial drill pipe steels are found in the SPE 25775 paper (Howard et al. [6]). The mean stress can affect the crack propagation by two following ways: the first way is that the mean stress changes the effective range of the SIF in the case of negative stress ratio by assuming that the crack just propagates with the positive value of the SIF; the second one relates to stress ratio term in the Walker law formula in the positive stress ratio case.

- The crack shape is assumed to remain semi-elliptical during the crack growth. Therefore, two points on the crack front are selected for iterative calculations of crack propagation. Obviously, the first is the deepest point (point $D$ ), and the second is any point on the crack front (point $P$ ). The influence of the choice of the second point on the crack propagation can be studied.

- The initial crack shape $(A 0$ and $B 0)$ is assumed before calculating the crack growth. Consequently, the influence of the initial crack shape and the evolution of the parameters during the crack growth are also studied.

- In practice, a large part of the crack growth life is due to the growth of a very small crack. Therefore, the choice of the final crack size (final crack depth) does not affect much the prediction of crack growth life. We consider the fatigue crack growth life as the number of loading cycles during which 
the crack depth grows up from $A 0$ to the cylinder thickness. The influences of initial crack size, the cylinder dimensions and the tension on the fatigue crack growth life are also studied.

\section{Problem description}

The passage of a drill pipe in a dog-leg (well trajectory curvature) causes a bending moment and the rotation produces the cyclic loading in the drill pipe. This is the main cause of drill pipe fatigue. Further, the drill pipe is subjected to a tensile or compressive mean stress (for a drill pipe close to the drill bit). The drill pipe body is considered as a hollow cylinder. Therefore, our problem will focus on a rotating hollow cylinder subjected to bending moment and tension.

In general, the crack is growing perpendicular to the principal stress. For a hollow cylinder subjected to bending and tension loads, the principal stress direction is the cylinder axis. Thus, the crack is supposed to be in a cylinder cross section.

Figs. 1a and $1 \mathrm{~b}$ show the cylinder circular cross section with a geometrical representation of the crack. The crack shape is assumed to be semi-elliptic with the ellipse center on the cylinder external surface (two-parameter model). The geometries of hollow cylinder and crack are described by the following dimensionless parameters: the dimensionless radius of the hollow cylinder $\left(R_{i n t} / T\right)$, the aspect ratio of the crack ellipse $(B / A)$ and the relative depth of the crack $(A / T)$. A generic point on the crack front is identified by the "normalized coordinate" (Fig. 1b):

$$
\xi=\frac{X_{p}}{H} ; \quad-1 \leq \xi \leq 1
$$

\section{Stress intensity factor assessment using numerical simulation}

\subsection{FE-mesh}

According to the symmetry of the problem, we model only a quarter of the cylinder with two planes of symmetry: cylinder axis plane $\left(y_{1} O_{1} z_{1}\right)$ and crack plane $\left(x_{1} O_{1} y_{1}\right)$. This is in the cases where the cylinder is loaded by a bending moment $M_{x 1}$ about the horizontal axis $O_{1} x_{1}$ and a tension $\left(T_{e}\right)$ (Fig. 3a). In the case of bending moment $M_{y 1}$ about the vertical axis $O_{1} y_{1}$, we have just one plane of symmetry: crack plane $\left(x_{1} O_{1} y_{1}\right)$, and we must model a half of the structure. 20-node hexahedral solid elements (CU20) are employed. The structure mesh is composed of two parts: the crack front mesh (most dense) and the remaining structure (coarse).

In this finite element model, the isotropic linear elasticity is used with the Poisson's ratio $\nu=0.3$ and the Young's modulus $E=2.0 E 11 \mathrm{~Pa}$.

\subsection{G-theta procedure}

Bending moment and tension cause the mode I loading of the defined crack in the cylinder. So we are interested in calculating the stress intensity factor $K_{I}$. CASTEM code offers a number of procedures to perform fracture mechanic analysis applicable to two- or three-dimensional modeling. In our case, the procedure G-theta [7] is used. This procedure calculates the energy release rate on the crack front by the G-theta method $[8,9]$. It helps to calculate the $J$-integral of a contour in the vicinity of the crack front region (in the case of linear elasticity, it is equal to the energy release rate ) and to extract the stress intensity factors $K_{I}, K_{I I}, K_{I I I}$. Using the solution of Westergaard for stress and displacements with the linear elasticity and plane strain conditions, the $J$-integral and the strain energy release rate $G$ are related to the stress intensity factor $K$ in the following equation:

$$
J=G=\frac{1-\nu^{2}}{E} K_{I}^{2}
$$

Hence:

$$
K_{I}=\sqrt{\frac{E . J}{1-\nu^{2}}}=\sqrt{\frac{E . G}{1-\nu^{2}}}
$$

This relationship allows the stress intensity factor $K_{I}$ to be calculated from the results of the G-theta procedure. 


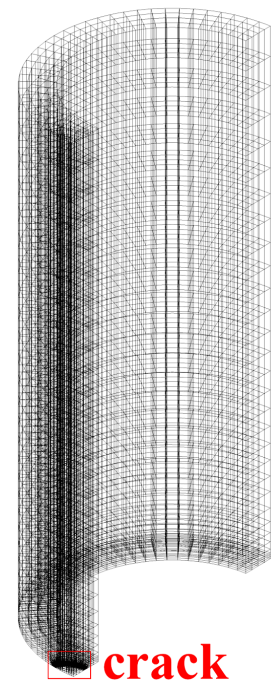

(a)

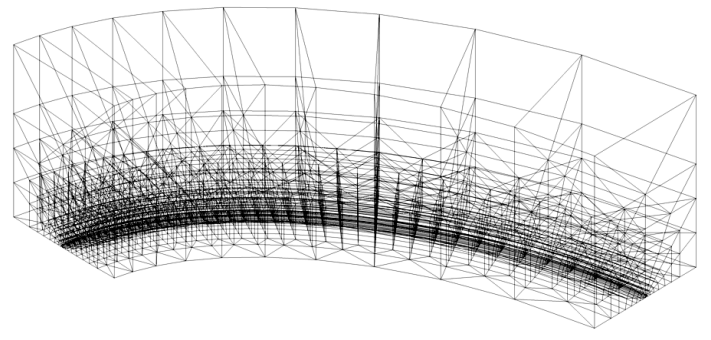

(b)

Figure 3: Finite element models: (a) A quarter of the cylinder, and (b) FE mesh of crack

\subsection{Stress intensity factor calculation method}

In our problem, the rotation of the cylinder is replaced by the rotation of the bending moment vector $M$. And this is represented by the variation of the angle $\psi$ between the bending moment $M$ and the horizontal axis $O_{1} x_{1}$ (Fig. 2). The bending moments $M_{x 1}$ and $M_{y 1}$ are related to the total bending moment $M$ by the equations:

$$
\left\{\begin{array}{l}
M_{x 1}=M \cdot \cos \psi \\
M_{y 1}=M \cdot \sin \psi
\end{array}\right.
$$

The SIF, $K_{I}$, is determined for three loading cases: bending moments $M_{x 1}, M_{y 1}$ and tension $T_{e}$ for each finite element model considered. The results are expressed by three dimensionless factors $F_{I, T_{e}}$, $F_{I, M_{x 1}}, F_{I, M_{y 1}}$ :

$$
\begin{gathered}
F_{I, T_{e}}=\frac{K_{I, T_{e}}}{T_{e} \sqrt{\pi a}} \\
F_{I, M_{x 1}}=\frac{K_{I, M_{x 1}}}{S_{a} \sqrt{\pi a}} ; \quad S_{a}=\frac{M_{x 1}}{I} R_{e x t} \\
F_{I, M_{y 1}}=\frac{K_{I, M_{y 1}}}{S_{a} \sqrt{\pi a}} ; \quad S_{a}=\frac{M_{y 1}}{I} R_{e x t}
\end{gathered}
$$

where $S_{a}$ is the maximum stress on the cross-section of the cylinder subjected to pure bending.

Considering a rotating hollow cylinder subjected to bending moment $M$ and tension $T_{e}, K_{I}$ is given by the following formula:

$$
K_{I}=\left[F_{I, T_{e}} \cdot T_{e}+F_{I, M_{x 1}} \cdot\left(S_{a, M} \cos \psi\right)+F_{I, M_{y 1}} \cdot\left(S_{a, M} \sin \psi\right)\right] \sqrt{\pi a}
$$

with:

$$
S_{a, M}=\frac{M}{I} R_{e x t}
$$

The dimensionless factor $F_{I}$ for the case of a rotating hollow cylinder subjected to a pure bending moment $M$ (without the tension $T_{e}$ ) is:

$$
F_{I, M}=\frac{K_{I}}{S_{a, M} \sqrt{\pi a}} \text { or } F_{I, M}=F_{I, M_{x 1}} \cdot \cos \psi+F_{I, M_{y 1}} \cdot \sin \psi
$$


The maximum and minimum values of $K_{I}$ when the cylinder makes one rotation (one loading cycle) are:

$$
\begin{aligned}
& K_{I, \max }=\left[F_{I, T_{e}} \cdot T_{e}+S_{a, M} \cdot \sqrt{F_{I, M_{x 1}}^{2}+F_{I, M_{y 1}}^{2}}\right] \sqrt{\pi a} \\
& K_{I, \min }=\left[F_{I, T_{e}} \cdot T_{e}-S_{a, M} \cdot \sqrt{F_{I, M_{x 1}}^{2}+F_{I, M_{y 1}}^{2}}\right] \sqrt{\pi a}
\end{aligned}
$$

$K_{I}$ reaches the maximum and minimum values with the angle below (in the case the point $P$ is in the left half of the crack front):

$$
\begin{gathered}
\psi_{\max }=\arctan \left(\frac{F_{I, M_{y 1}}}{F_{I, M_{x 1}}}\right) \\
\psi_{\min }=\arctan \left(\frac{F_{I, M_{y 1}}}{F_{I, M_{x 1}}}\right)+\pi
\end{gathered}
$$

\subsection{Results of stress intensity factor calculations}

Figs. $4 \mathrm{a}$ and $4 \mathrm{~b}$ show the results of SIF calculations for the bending moment case $\left(M_{x 1}\right.$ in Fig. 2$)$ and the tension case, respectively. The ordinate axis represents the dimensionless factor $F$ and the horizontal axis represents the position of the point on the crack tip. The calculations are made with $R_{\text {int }} / T=10$ and different values of the ratios $A / T$ and $B / A$ reported in the figures.

On the same figures, we represent the results of Shahani and Habibi [10] using the 3D finite element ANSYS 7.0 code. The analysis of Shahani et al. is performed using the sub-model method; first the structure is modeled by a large mesh, then the region of interest (here it is the region around the crack), which needs very fine mesh, is cut from the large mesh model, and analyzed with another high-density mesh. Comparisons shown in Figs. 4 indicate that our results using CASTEM code are close to those of Shahani et al.

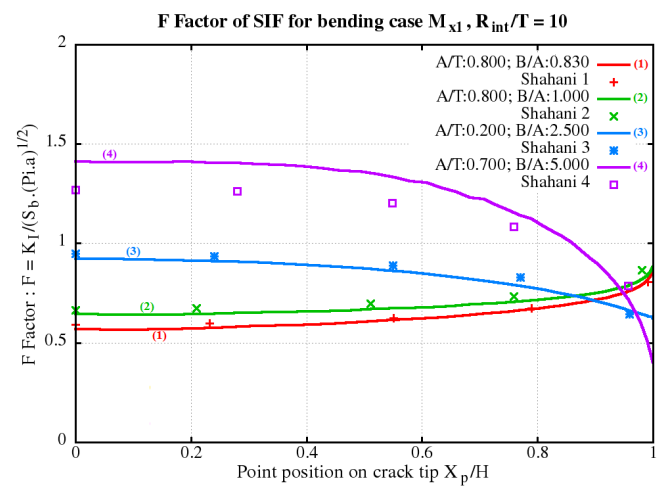

(a)

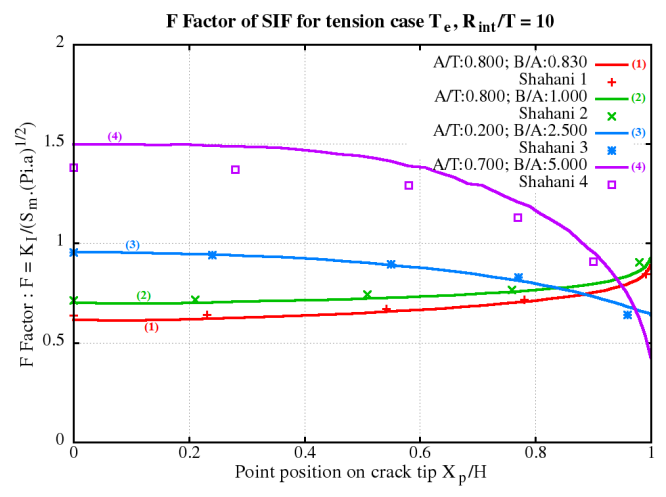

(b)

Figure 4: Numerical results - comparisons with the results of Shahani [10]: (a) Bending case, and (b) Tension case

In Figs. 5 and 6, the results for the rotary bending case (solid curves) and the cyclic bending case (dotted curves) are presented. The rotary bending case represents a cylinder subjected to a constant bending moment and this cylinder is rotating, while the cyclic bending case represents a cylinder subjected to a cyclic bending moment (the cylinder does not rotate but the bending moment is cyclic). The dimensionless factor $F$ of the rotary bending case is determined from the results of CASTEM code model using Eq. 10. In the case of a cyclic bending moment, the effect of bending moment $M_{y 1}$ is excluded. So we can use Eq. 10 without the $F_{I, M_{y 1}}$ term.

Figs. 5 and 6 show the relationship of the SIF dimensionless factor $F$ with the normalized coordinate $X p / H$. The parameters of the calculations in Figs. 5 are $A / T=0.5, B / A=5$ or 1 , and various values of $\psi$. For the results shown in Figs. 6 , we consider $A / T=0.2$ or $0.8, \psi=30^{\circ}$ or $60^{\circ}$, and various values of 

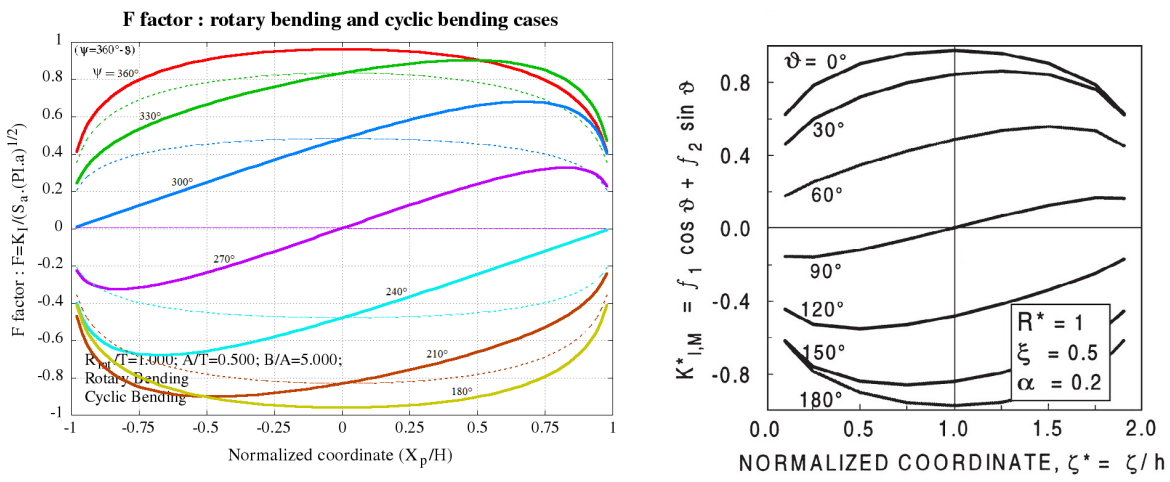

(a)
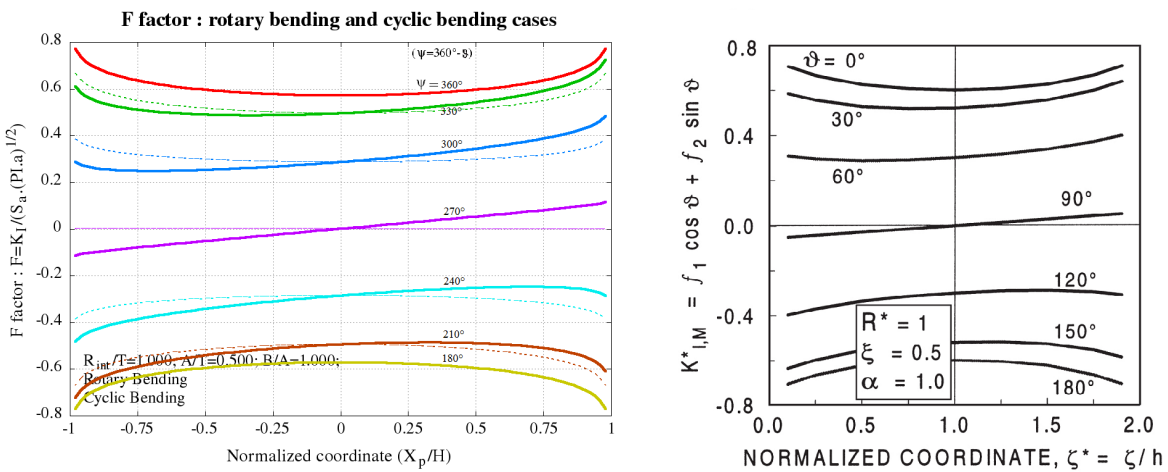

(b)

Figure 5: Numerical results - comparisons with the results of Carpinteri [5]: (a) $R_{\text {int }} / T=1, A / T=0.5$, $B / A=5$ and different values of $\psi$, and (b) $R_{\text {int }} / T=1, A / T=0.5, B / A=1$ and different values of $\psi$.

$B / A$. In some cases, the gap between rotary bending and cyclic bending is very important. However, the difference in the SIF range completely depends on the factor $F_{I, M_{y 1}}$ shown in Eqs. 11 and 12 (depending on the cylinder and crack geometries and the position of the point considered on the crack front).

Carpinteri et al. [5] presented results related to a thick-wall pipe $\left(R^{*}=R_{\text {int }} / T=1\right)$ for the same rotary bending cases (figures on the right). In the results by Carpinteri, the crack ellipse aspect ratio $\alpha$ is equal to $A / B, \vartheta$ represents the angle of bending moment and is equal to $(360-\psi)$. The normalized coordinates $X_{p} / H=-1$ and $X_{p} / H=1$ in the case of our calculation correspond respectively to $\zeta^{*}=0$ and $\zeta^{*}=2$ in Carpinteri's results. There is a small difference between our results and those by Carpinteri, and that can be caused by the different mesh and the used finite element code. However our results for the rotary bending case generally agree with the results by Carpinteri et al.

\section{Determination of fatigue crack growth}

\subsection{Crack growth rate law}

The Paris law is the simplest and the most commonly used law governing crack propagation. This law assumes a linear relationship of $d a / d N$ with $\triangle K$ in the logarithm coordinate:

$$
\frac{d a}{d N}=C(\triangle K)^{n}
$$

where $C$ and $n$ are the coefficient and the slope of the crack growth rate, respectively. Table 1 shows these coefficients for various commercial drill pipe materials (with $d a / d N$ in in./cycle and $\triangle K$ and in ksi.in. ${ }^{1 / 2}$ ) [5].

A disadvantage of the Paris law is that it does not take account of the mean stress. Thus, in this paper, we consider the commonly used empirical relationship Walker law given by Eq. 16: 


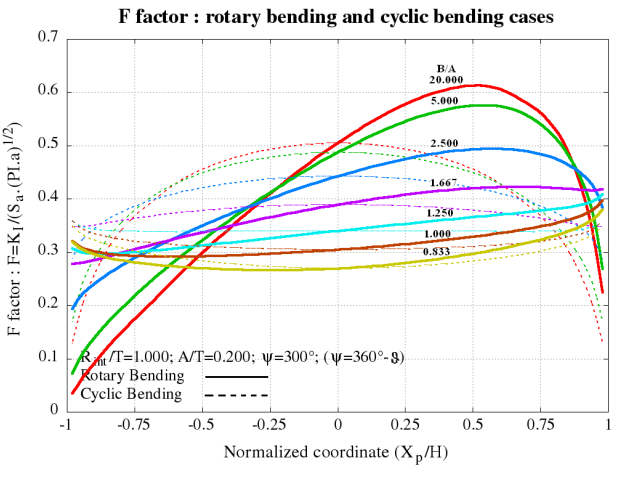

(a)

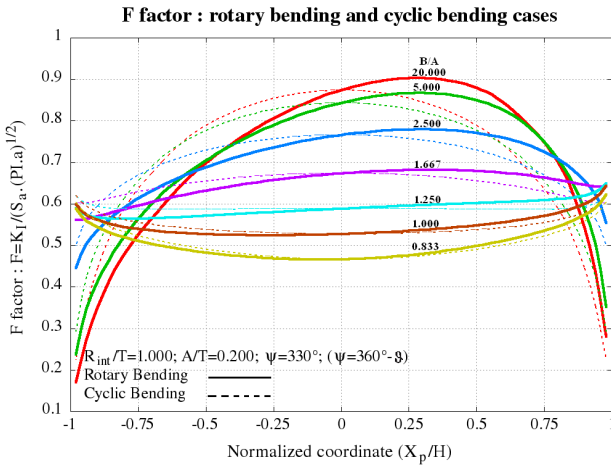

(b)
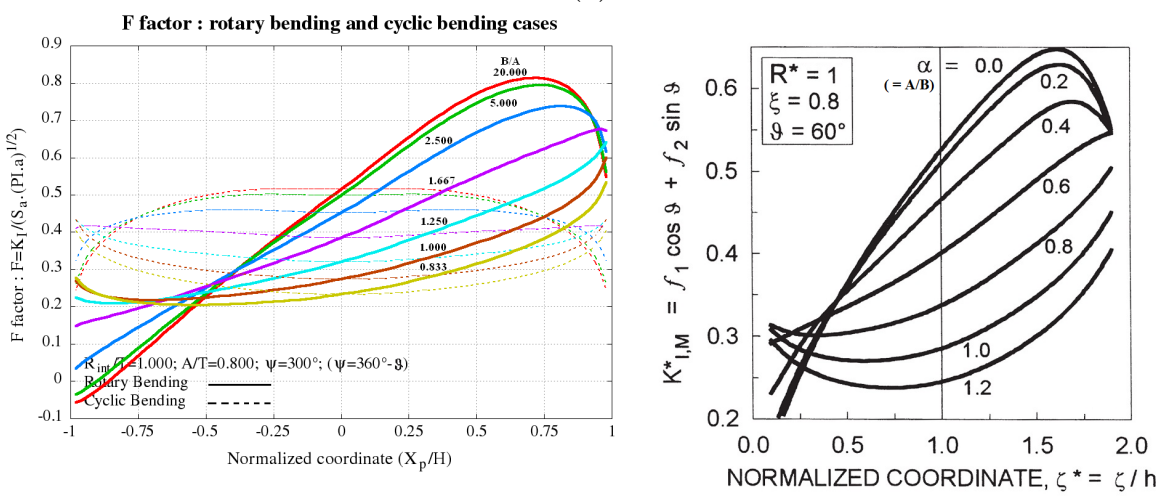

(c)
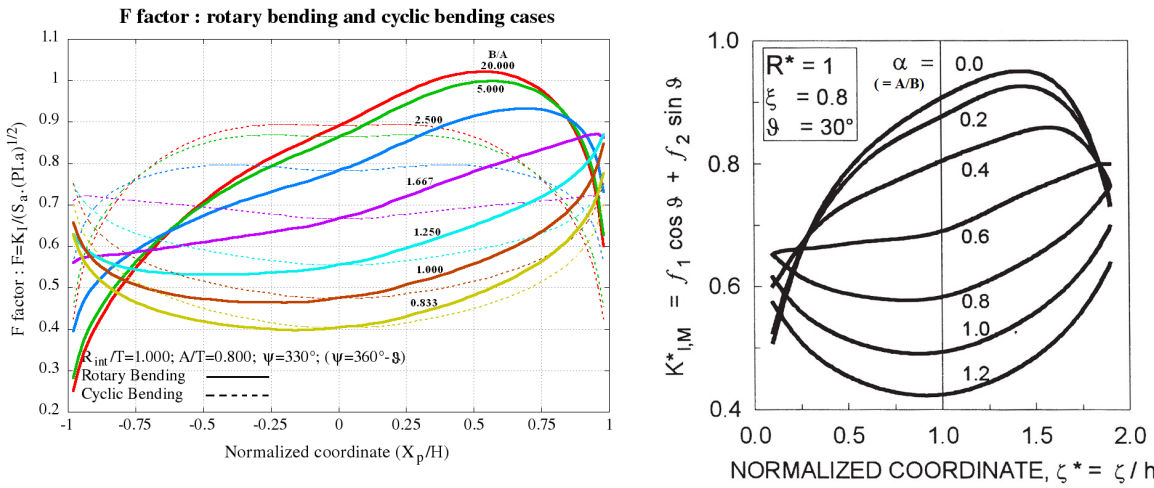

(d)

Figure 6: Comparisons with the results of Carpinteri [5]: (a) $R_{\text {int }} / T=1, A / T=0.2, \psi=60^{\circ}$ and different values of $B / A$, (b) $R_{\text {int }} / T=1, A / T=0.2, \psi=30^{\circ}$ and different values of $B / A$, (c) $R_{\text {int }} / T=1$, $A / T=0.8, \psi=60^{\circ}$ and different values of $B / A$, (d) $R_{\text {int }} / T=1$, and $A / T=0.8, \psi=30^{\circ}$ and different values of $B / A$. 
Table 1: Crack growth rate coefficients for various drill pipe materials (SPE 25775) (Howard et al. [6])

\begin{tabular}{lcc}
\hline Type of Material & $\mathbf{n}$ & $\mathbf{C}$ \\
\hline API Grade E & 2.94 & $4.41 \times 10^{-10}$ \\
API Grade X & 2.65 & $9.35 \times 10^{-10}$ \\
API Grade G & 2.52 & $1.60 \times 10^{-9}$ \\
API Grade S & 2.52 & $1.60 \times 10^{-9}$ \\
4145 MOD Steel (box) & 2.68 & $1.152 \times 10^{-9}$ \\
4145 MOD Steel (pin) & 3.07 & $3.083 \times 10^{-10}$ \\
\hline
\end{tabular}

$$
\frac{d a}{d N}=C\left[\frac{\triangle K}{(1-R)^{(1-\lambda)}}\right]^{n}
$$

where $C$ and $n$ are Paris law coefficient and slope for $R=0$ respectively, $\lambda$ is a material coefficient and $R$ is the stress ratio:

$$
R=\frac{K_{\min }}{K_{\max }}
$$

The Walker law is valid for $R \geq 0$. The effect of negative $R$ ratios, which includes compression in the cycle, has received less investigation and is less understood. The compressive load part of fatigue is not taken into consideration on most of fatigue codes. It is not included in the calculation of the stress intensity factor range, $\Delta K$. As a matter of fact, it is assumed that when the load is negative the crack is closed and there is no growth of the crack when it is not open. So in the negative stress ratio case, we consider $R$ equal to 0 in the Walker law formula and the SIF range calculation is shown in Section 4.3 (in the tension-compression loading case, the $\Delta K$ is equal to $K_{\max }$ shown in Eqs. 25-27).

$$
R=0 \quad \text { if } \quad R<0
$$

\subsection{Stress intensity factor solution}

The SIF is given by expressions including the F-factors corresponding to a given configuration of geometry and loading. These F-factors are based on three variables $\left(R_{\text {int }} / T, A / T\right.$ and $\left.B / A\right)$. From the results of finite element simulations, we constructed an F-factor database with discrete values corresponding to wide range of $R_{\text {int }} / T, A / T$ and $B / A$. Using this table, we apply the linear interpolation method of three variables in order to assess the for arbitrary values of $R_{\text {int }} / T, A / T$ and $B / A$ using Eq. 19:

$$
F(x, y, z)=\sum_{i=1}^{2} \sum_{j=1}^{2} \sum_{k=1}^{2} X_{i}(x) Y_{j}(y) Z_{k}(z) F\left(x_{i}, y_{j}, z_{k}\right)
$$

where $x, y, z$ are the variables replacing $R_{\text {int }} / T, A / T$ and $B / A$, respectively. $X_{i}(x), Y_{j}(y), Z_{k}(z)$ are the interpolation polynomials of degree equal to one (linear interpolation):

$$
\begin{aligned}
& X_{i}(x)=\left(\frac{x-x_{m}}{x_{i}-x_{m}}\right)_{m=1,2 ; m \neq i} \\
& Y_{j}(y)=\left(\frac{y-y_{m}}{y_{j}-y_{m}}\right)_{m=1,2 ; m \neq j} \\
& Z_{k}(z)=\left(\frac{z-z_{m}}{z_{k}-z_{m}}\right)_{m=1,2 ; m \neq k}
\end{aligned}
$$




\subsection{Crack growth calculating algorithm}

Crack propagation is determined for each $\Delta N$ loading cycle. The crack shape is assumed to remain semi-elliptical during the propagation. Hence, two points on the crack front are selected for iterative calculations: the first is the deepest point $D$, and the second is any point $P$ on the crack front. The influence of the choice of the second point on the crack propagation is taken into account in the following.

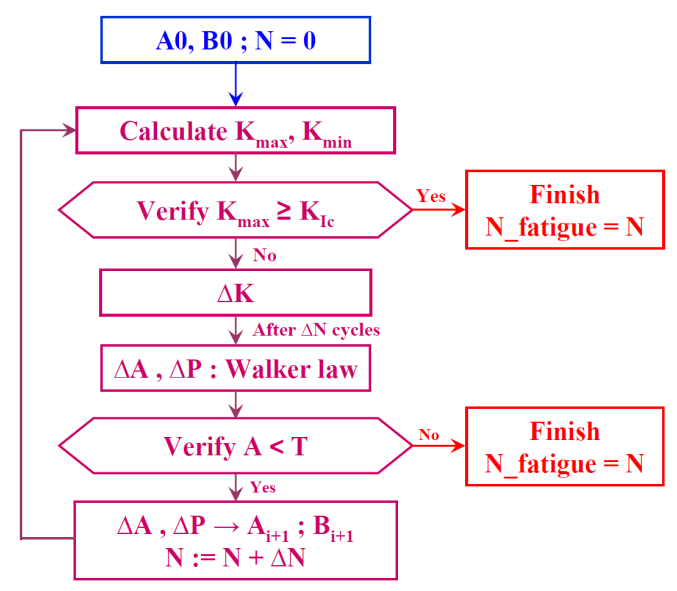

(a) Histogram of crack growth calculating algorithm

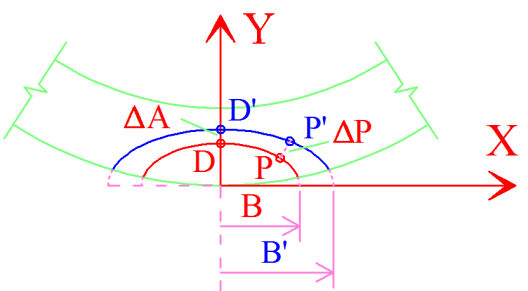

the crack propagates after one calculation iteration of $\Delta \mathrm{N}$ cycles

(b) A calculation iteration

Figure 7

After $\Delta N$ cycles, the crack develops and the points $D, P$ propagate to the points $D^{\prime}, P^{\prime}$ respectively. The propagation direction of a point is perpendicular to the ellipse asymptote on this point. The crack shape before and after the calculation iteration is given by the following Eqs. 23 and 24:

$$
\begin{aligned}
& \left(\frac{X}{B}\right)^{2}+\left(\frac{Y}{A}\right)^{2}=1 \\
& \left(\frac{X}{B^{\prime}}\right)^{2}+\left(\frac{Y}{A^{\prime}}\right)^{2}=1
\end{aligned}
$$

where $A, B$ and $A^{\prime}, B^{\prime}$ are the two crack ellipse radius before and after the calculation iteration respectively. Therefore, if we know the coordinates of points $D^{\prime}$ and $P^{\prime}$, the crack shape after $\Delta N$ cycles is determined through the $A^{\prime}$ and $B^{\prime}$ values (Fig. 7b).

$K_{\max }$ and $K_{\min }$ values are calculated using Eqs. 11 and 12 . We assume that the crack propagates when the SIF is positive. Furthermore, in this study, we do not take into account the crack closure effect because we do not have enough data for the studied material. Hence, the SIF range during a loading cycle being introduced into the crack growth rate law equation is calculated by the following Eqs. 25-27.

If the calculated $K_{\max }$ is negative, we replace the SIF range by zero:

$$
K_{\max } \leq 0 \Rightarrow \triangle K=0
$$

If the $K_{\max }$ is positive and $K_{\min }$ is negative:

$$
K_{\max }>0 ; K_{\min }<0 \Rightarrow \triangle K=K_{\max }
$$

else:

$$
K_{\max }, K_{\min } \geq 0 \Rightarrow \triangle K=K_{\max }-K_{\min }
$$

The criteria by stress stipulate that the crack becomes unstable when the SIF exceeds a certain limit value which is called the fracture toughness. Therefore, if we know the fracture toughness $K_{I c}$ of the material studied, we must compare the calculated SIF with the material fracture toughness in a calculating iteration. If the calculated SIF exceeds the toughness $K_{I c}$, we consider that the structure 
is failed and we stop the calculations. Fig. 7a illustrates the algorithm developed to assess the crack growth.

\section{Crack propagation under combined loading}

The purpose is to assess the propagation of a semi-elliptical external surface crack in a hollow cylinder under a combination of rotary bending moment and tension. The cylinder is made of grade E drill pipe steel. Walker law coefficients are those given in Table 1. No value of the constant $\lambda$ in Walker's formula is found in the literature for the grade $\mathrm{E}$ drill pipe steel. We consider a value of $\lambda$ equal to 0.5 without additional data for studying the mean stress effect.

An example of crack propagation is illustrated in Figs. 8. The cylinder dimensions are $D_{\text {ext }}=4.500$ in. and $D_{\text {int }}=3.640 \mathrm{in}$. The crack propagates from the initial size $(A 0=0.025 \mathrm{in}$.) to the final size (the crack depth $A$ reaches the cylinder thickness) with the loadings $S_{a}=50 \mathrm{ksi}$ and $T_{e}=10 \mathrm{ksi}$. The initial crack geometry is given by $B 0 / A 0=1$ in Fig. 8 a and $B 0 / A 0=10$ in Fig. 8 b.

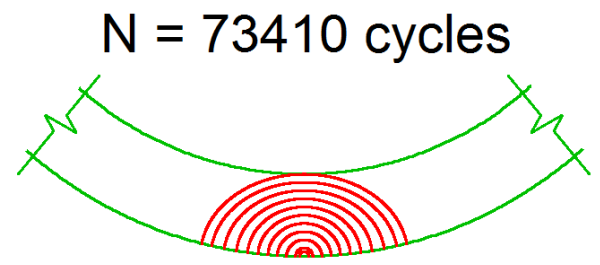

(a)

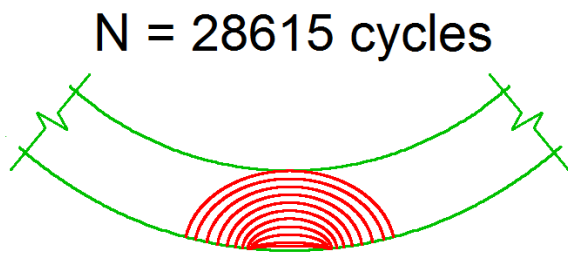

(b)

Figure 8: Crack propagation example: (a) $B 0 / A 0=1$, and (b) $B 0 / A 0=10$.

\subsection{Convergence of the crack ellipse aspect ratio $B / A$}

Crack propagation under combination of rotary bending moment and tension has been studied by using the two-parameter theoretical crack model. This study shows that, for a given cylinder, the crack geometry tends to converge to a unique final geometry $(B / A)_{\text {final }}$ during the propagation, whatever the initial crack geometry defined by the $B 0 / A 0$ value. This conclusion is illustrated in Figs. 9 giving crack propagation at different values of initial aspect ratio $B 0 / A 0$ of crack ellipse. The curves represent the evolution of the crack ratio $B / A$ as a function of the relative crack depth $A / T$ under various loading combinations $\left(S_{a}, T_{e}\right)$. The cylinder dimensions are $4.5 \mathrm{in}$. for the outer diameter and $3.640 \mathrm{in}$. for the inner diameter. $X_{p} / H$ is the normalized coordinate (Eq. 1) of the second point $P$ chosen for crack propagation calculations.

Let's focus on the parameters which can influence the value of $(B / A)_{\text {final }}$. For these calculations, the initial crack geometry is $A 0=B 0=0.005$ in. (Fig. 10a) and $A 0=0.005$ in., $B 0=2 A 0=0.01$ in. (Fig. 10b). Figs. 10a and $10 \mathrm{~b}$ represent the evolution of $(B / A)_{\text {final }}$ with the bending stress amplitude $S_{a}$ for various values of tension $T_{e}$.

We note that the tension may decrease the value of $(B / A)_{\text {final }}$. There are two different parts on the $(B / A)_{\text {final }}$ - bending stress $S_{a}$ curve. This function seems to have a discontinuity at a value of bending stress close to the applied tension, which may make the $K_{\min }$ in Eq. 12 equal to zero at certain crack geometry. This is due to the fact that, in the case of negative $K_{\min }$ (e.g. compression - tension cycle), the SIF range is taken equal to $K_{\max }$. In this study, we consider $R=0$ and $\triangle K=K_{\max }$ for the Walker law formula when $R<0$. Therefore, the part of compressive stress in the load cycle is neglected in the crack propagation calculation.

We find that the curve of the fully reversed case $T_{e}=0(R=-1)$ is horizontal. That is, $(B / A)_{\text {final }}$ does not depend on the bending stress $S_{a}$ in this case. The curves in Figs 10 seem to show that $(B / A)_{\text {final }}$ is a function of the ratio $\left(S_{a} / T_{e}\right)$ for a given cylinder geometry. For example, we can see the square points in Figs 10. At these points, the $\left(S_{a} / T_{e}\right)$ value is equal to 2 and $(B / A)_{\text {final }}$ nearly takes the same value. In the case of $T_{e}=0,\left(S_{a} / T_{e}\right)$ tends to infinity for all Sa values; thus $(B / A)_{\text {final }}$ is constant. 


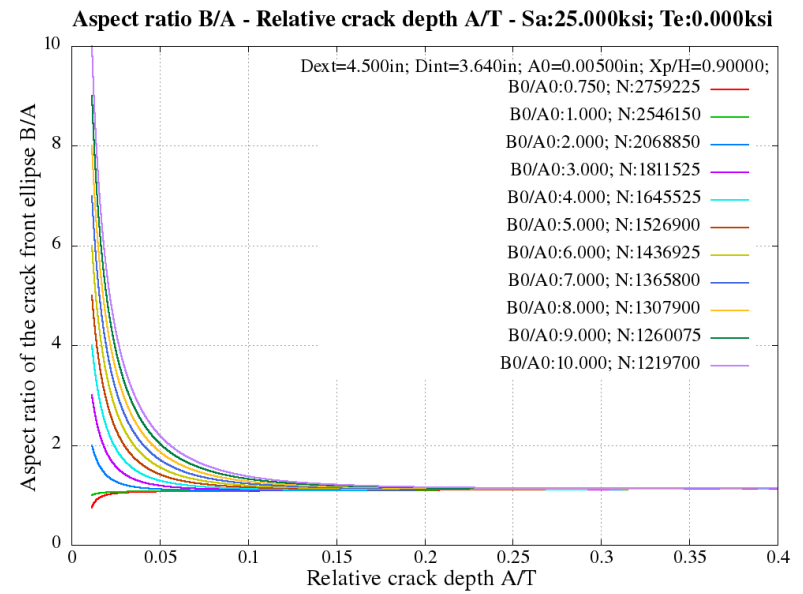

(a)

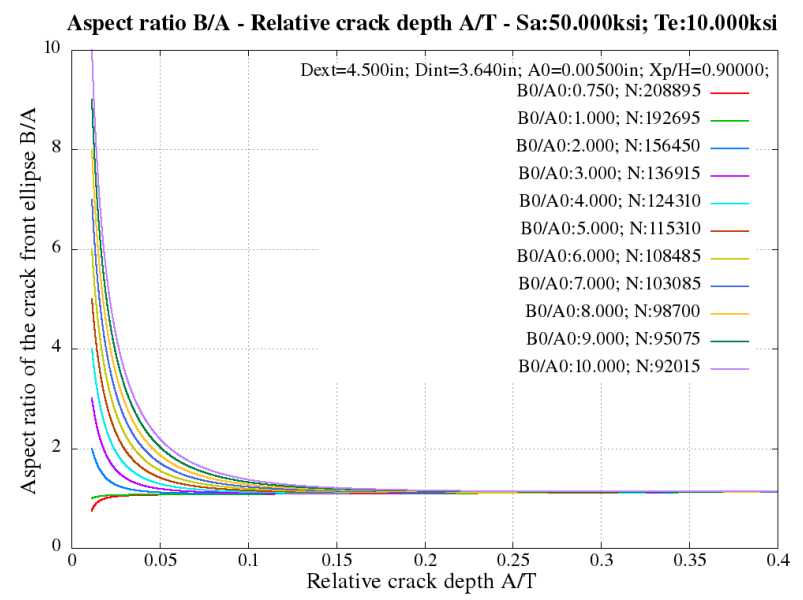

(c)

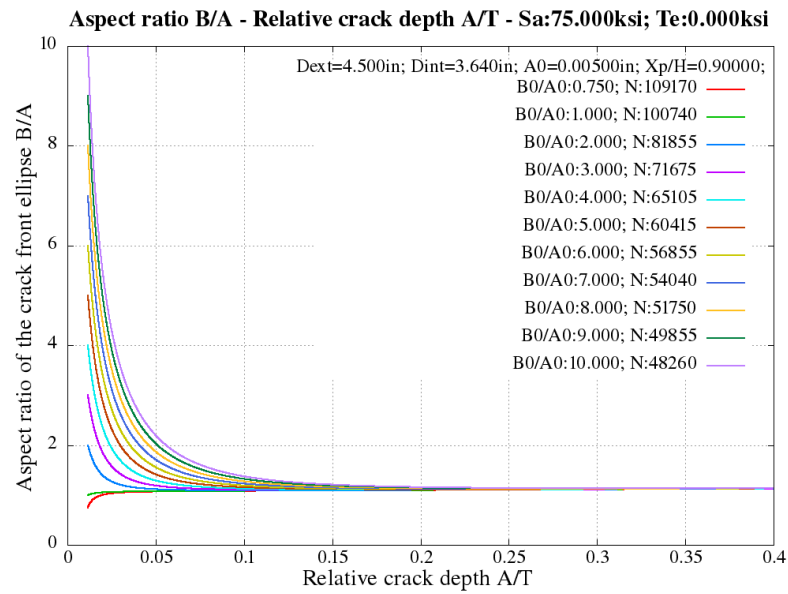

(b)

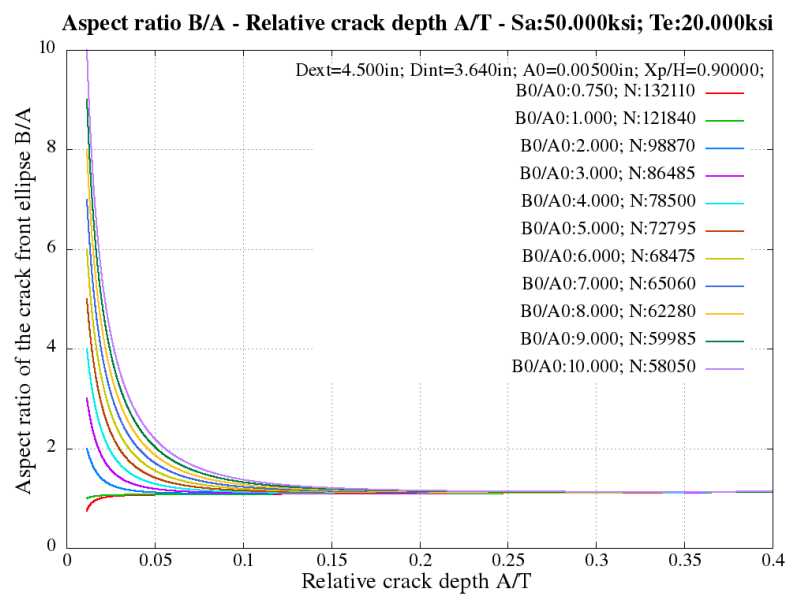

(d)

Figure 9: Evolution of the crack ellipse aspect ratio B/A: (a) $S_{a}=25 \mathrm{ksi}$ and $T_{e}=0 \mathrm{ksi}$, (b) $S_{a}=75 \mathrm{ksi}$ and $T_{e}=0 \mathrm{ksi},(\mathrm{c}) S_{a}=50 \mathrm{ksi}$ and $T_{e}=10 \mathrm{ksi}$, (d) $S_{a}=50 \mathrm{ksi}$ and $T_{e}=20 \mathrm{ksi}$.

\subsection{Crack depth - number of cycles}

Figs. 11 represent the evolution of the relative crack depth $A / T$ against the number of cycles. We may note that the greater the crack depth, the higher the crack growth rate. The number of cycles required for the crack to propagate through a distance equal to a half of cylinder thickness takes most of fatigue propagation life. This confirms the well-known conclusion that a large part of crack propagation life is due to the propagation of a very small crack. Thus, we consider the crack propagation life $N$ as the number of cycles at which the crack develops from the initial depth $A 0$ to the cylinder thickness. The crack propagation lives $N$ for various cases are presented below.

\section{3. $S$ - $N$ curve computation}

We study the effect of cylinder and initial crack geometries as well as the applied tension on the crack propagation life. The crack propagation life curves for various cases of cylinder geometry are presented in Fig. 12a. We set the initial crack geometry to $A 0=B 0=0.005$ in., the tension to $T_{e}=0 \mathrm{ksi}$, the normalized coordinate of the second propagation point $P$ to $X_{p} / H=0.9$. Three cylinders with the same outer diameter but different thicknesses are considered for calculations. We may note that the cylinder dimensions almost do not affect the crack propagation life.

The effect of initial crack geometries is reported in Fig. $12 \mathrm{~b}$ with $B 0 / A 0$ varying from 1 to 5 . The results indicate that the greater the initial crack ratio $B 0 / A 0$, the lower the crack propagation life. The initial crack depth is set constant at $A 0$.

Fig 12c illustrates the effect of the normalized coordinate $X_{p} / H$ of the second propagation point $P$ on the S-N curve when this parameter varies from 0.5 to 0.9 . We have almost the same curves of crack 


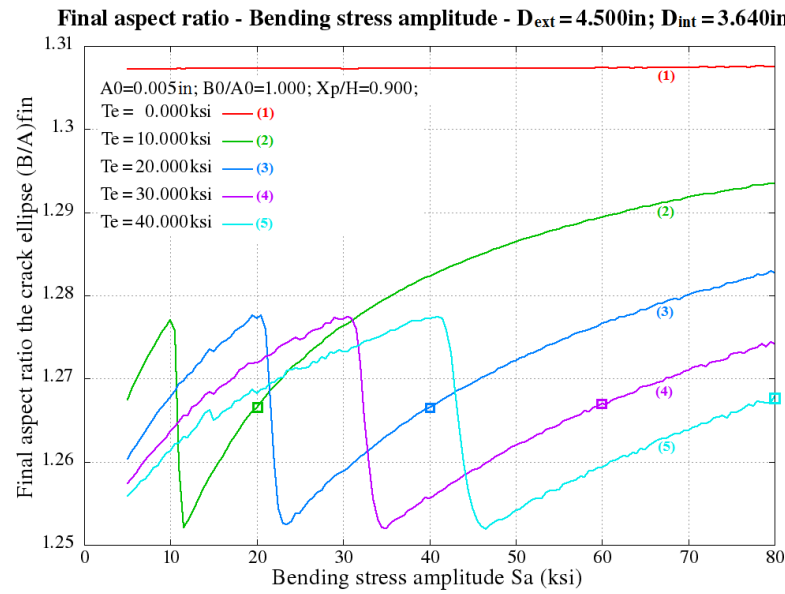

(a)

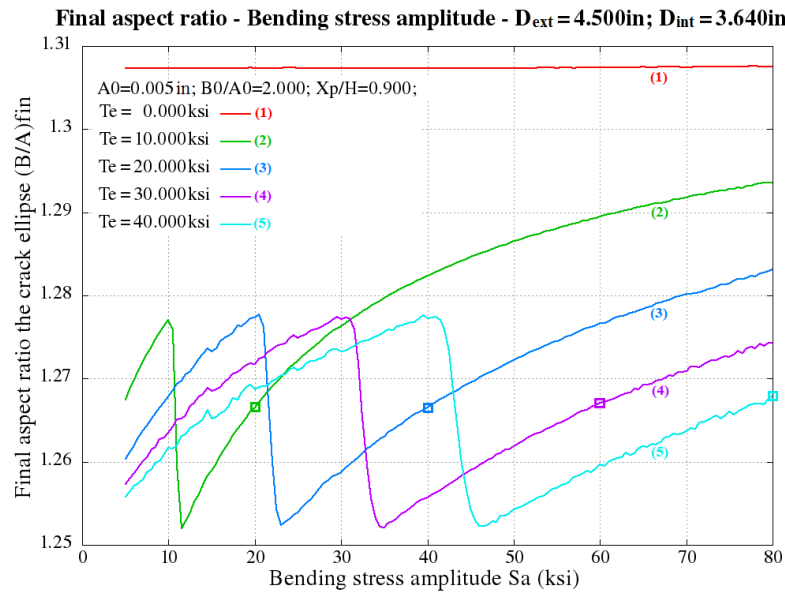

(b)

Figure 10: Converged value of the crack ellipse aspect ratio $B / A$ : (a) $B 0 / A 0=1$, (b) $B 0 / A 0=2$.

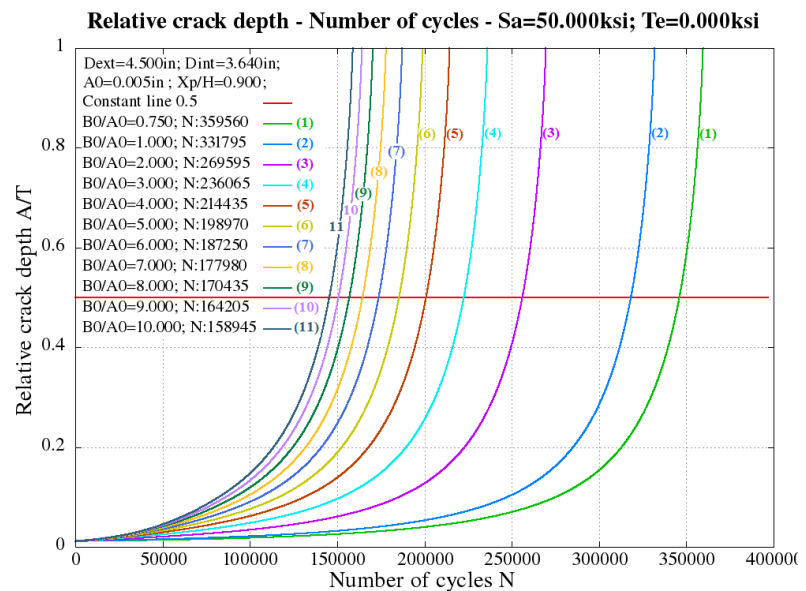

(a)

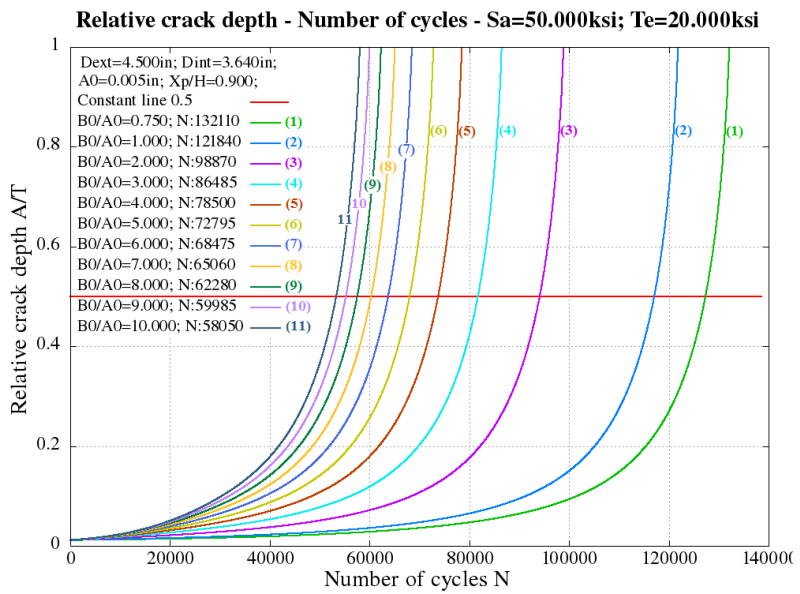

(b)

Figure 11: Evolution of crack depth against number of cycles: (a) $S_{a}=50 \mathrm{ksi}$ and $T_{e}=0 \mathrm{ksi}$, (b) $S_{a}=50$ ksi and $T_{e}=20 \mathrm{ksi}$.

propagation life - stress amplitude for five different cases of point $P$. Therefore, the choice of the second propagation point does not influence much on the crack propagation life.

In our model, the tension influences the crack propagation due to the stress ratio term in the Walker law formula in the case of tension-tension loading (positive R-ratio). In the case of tension-compression loading, tension changes the effective range of SIF which is introduced in the crack propagation calculations. We consider that the part of compressive stress in the loading cycle does not affect the crack propagation. Fig. 12d represents crack propagation life for various values of tension. It is obvious that tension decreases the crack propagation life. We may note the existence of a transition point on the S-N curve. This corresponds to the value of the bending stress which may make the minimum value of SIF equal to zero (transition between the tension-tension case and the tension-compression case). From this value, the tension does not change the SIF range anymore, and the crack propagation is only influenced by the stress ratio term in Walker law formula.

\subsection{Crack propagation algorithm for rotary drilling operation}

A crack growth model in drill pipe has been developed in section 4.3. As a part of its research program on Oil\&Gas drilling, the Mines-ParisTech University has developed a numerical code (ABIS) (Sikal et al. [11]) that can predict the mechanical behavior of a stiff drill string inside the drilled well with any complex shape including tortuosity and micro-tortuosity. The operational model of crack propagation uses the 


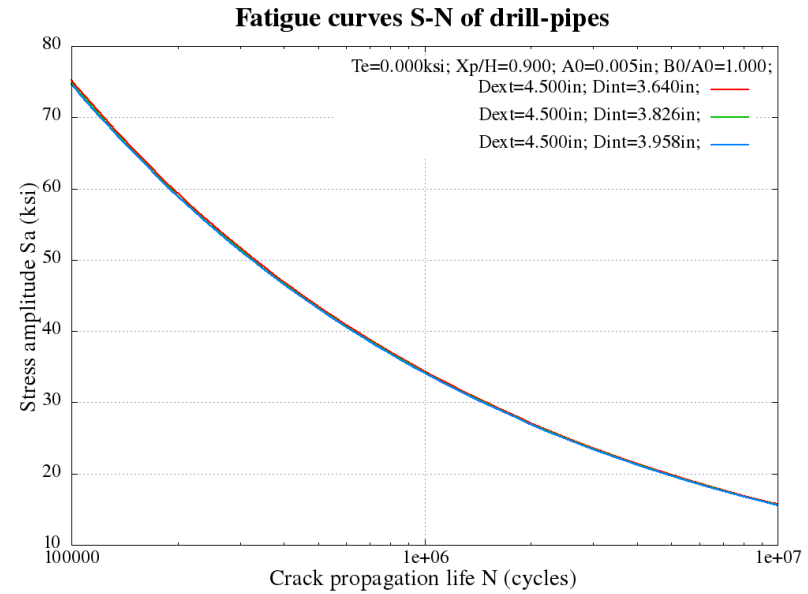

(a)

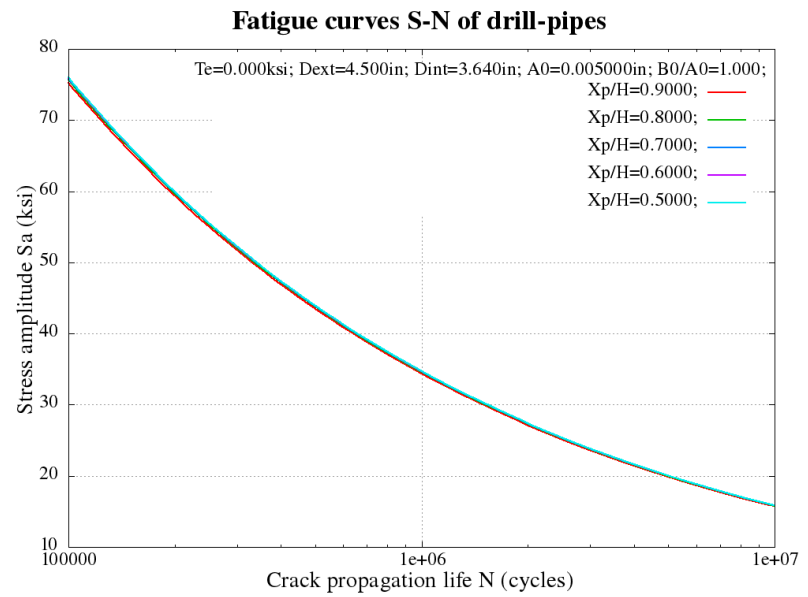

(c)

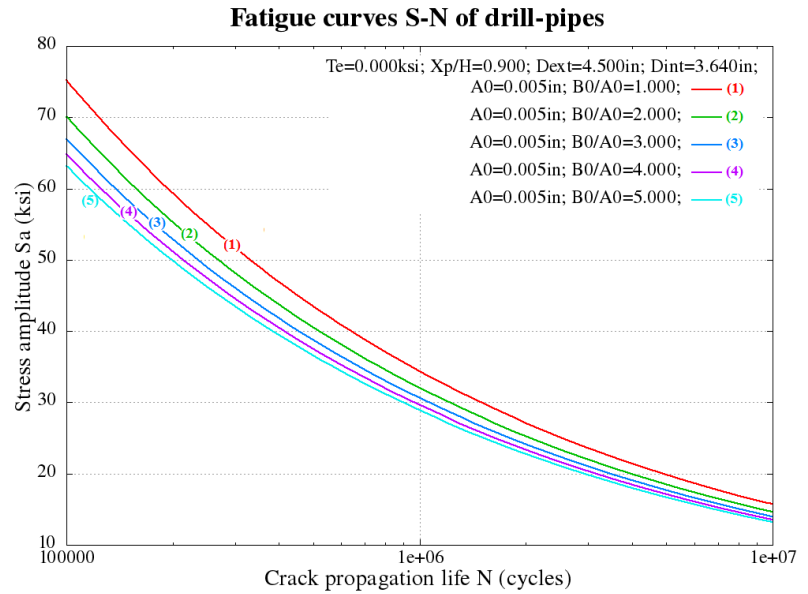

(b)

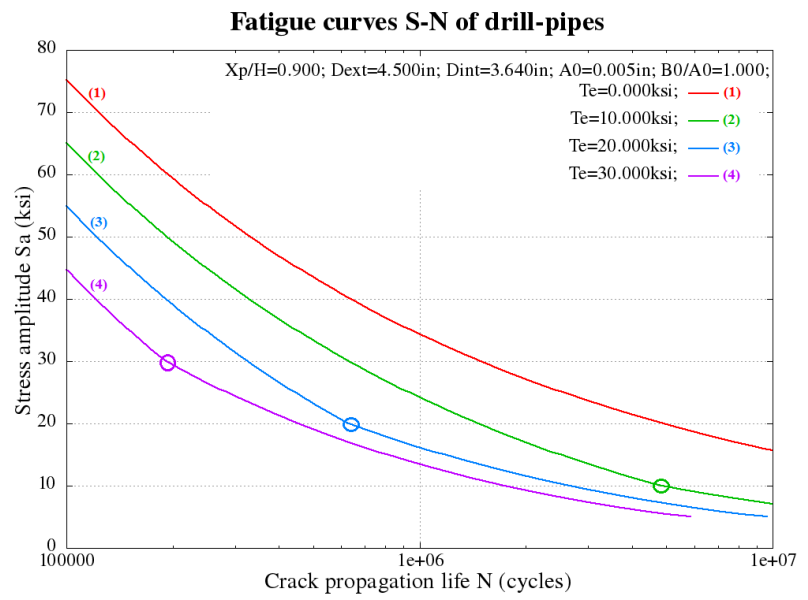

(d)

Figure 12: S-N curve computation for drill pipe: (a) different cylinder thicknesses, (b) different initial crack geometries, (c) different choices of the second propagation point $P,(\mathrm{~d})$ different tension loadings.

ABIS code that allows to calculate the drill string deformation inside the well and to predict accurately the stresses in the drill pipes as well as the contact forces between drill pipes and the borehole.

The algorithm of the crack propagation model during rotary drilling operation is shown in Fig. 13. The calculations are performed step by step, and we consider that drilling operation evolves by steps of length $\triangle L_{i}$. In each computation step, the ABIS code is used to determine accurately the stresses in the drill string. Next, the crack propagation code is implemented to determine the crack evolution.

\section{Conclusions}

The behavior of a circumferential semi-elliptical crack on the external surface of a hollow cylinder subjected to a combination of rotary bending and tension is studied. Various finite element simulations were performed under three loading modes: bending moments $M_{x 1}, M_{y 1}$ and tension $T_{e}$. The results are used to build a SIF database from which the SIF is calculated by using a polynomial interpolation method.

The Paris law widely used in the literature does not take into account the mean stress effect (or the tension). In order to overcome this limitation, we used the Walker law for computing crack propagation. The numerical results using the developed model show a very important role of the tension on the fatigue crack growth.

The simulation indicates that crack has a tendency to converge to a final geometry whatever its initial geometry, as described by other studies in which only initial crack geometry has been varied. Studies of the final crack geometry were conducted using as a parameter the final value of the ellipse crack aspect 


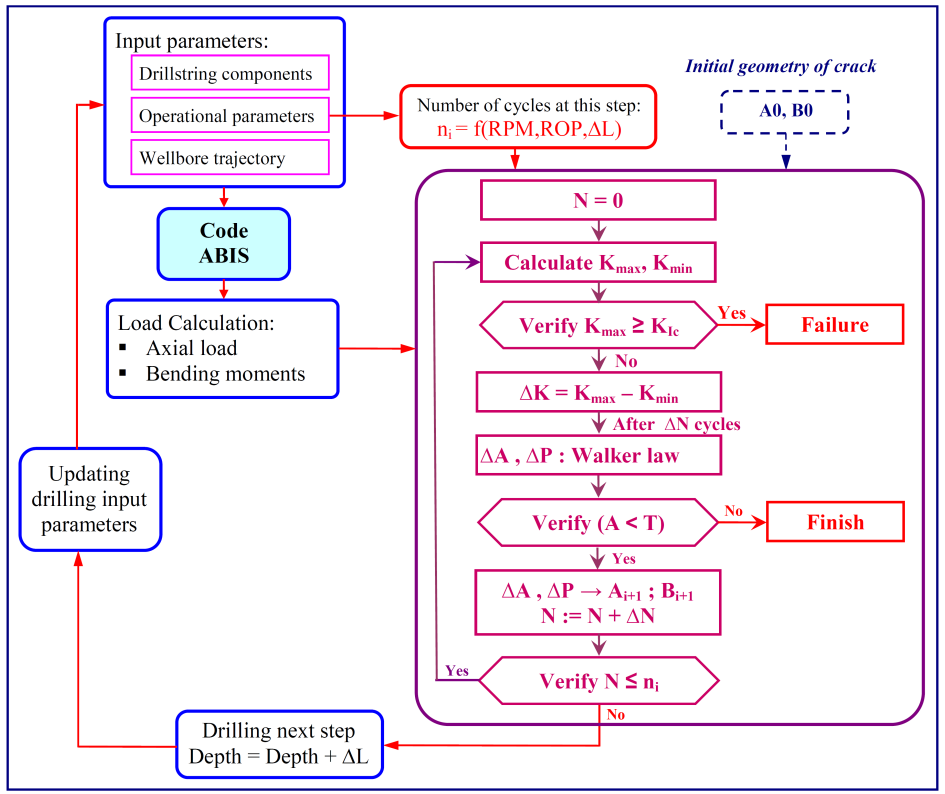

Figure 13: Crack propagation algorithm for rotary drilling operation.

ratio $(B / A)_{f i n a l}$. This study shows that the tension may decrease the $(B / A)_{f i n a l}$ value, and there is a transition point on the curve $(B / A)_{\text {final }}-S_{a}$. Additionally, $(B / A)$ does not depend on the bending stress in the alternating symmetrical case $\left(R=-1\right.$ or $\left.T_{e}=0\right)$, and it seems that $(B / A)_{\text {final }}$ is a function of the ratio $\left(S_{a} / T_{e}\right)$ for a given cylinder geometry.

It is well accepted that a large part of crack propagation life is due to the propagation of a very small crack. Thus, we considered that the life of crack propagation corresponds to the number of cycles at which the crack develops from the initial depth $A 0$ to the cylinder thickness. This definition allows us to construct the S-N curves of drill pipes using this developed model. Studies of S-N curves resulting from this model show the important influences of the initial crack size and the tension on the crack propagation life, while the effect of the cylinder dimension and the choice of second crack propagation point are low.

This crack growth model requires the knowledge of the Walker law coefficients. Therefore, it is necessary to perform fatigue crack growth rate tests to determine these coefficients for different steel grades used in drill pipes. Using these results, it is possible to simulate the crack evolution in a drill pipe.

\section{References}

[1] X. B. Lin, R. A. Smith, Fatigue growth prediction of internal surface cracks in pressure vessels, Journal of pressure vessel technology - Trans ASME 120 (1) (1998) 17-23, ISSN 0094-9930.

[2] A. Carpinteri, R. Brighenti, A three-parameter model for fatigue behaviour of circumferential surface flaws in pipes, International Journal of Mechanical Sciences 42 (7) (2000) 1255 - 1269, ISSN 00207403.

[3] A. Carpinteri, R. Brighenti, Circumferential surface flaws in pipes under cyclic axial loading, Engineering Fracture Mechanics 60 (4) (1998) 383 - 396, ISSN 0013-7944.

[4] A. Carpinteri, R. Brighenti, A. Spagnoli, Part-through cracks in pipes under cyclic bending, Nuclear Engineering and Design 185 (1) (1998) 1 - 10, ISSN 0029-5493.

[5] A. Carpinteri, R. Brighenti, A. Spagnoli, Fatigue growth simulation of part-through flaws in thickwalled pipes under rotary bending, International Journal of Fatigue 22 (1) (2000) 1 - 9, ISSN 0142-1123.

[6] J. Howard, M. Halbert, A. Lubinski, Systematic Tracking of Fatigue and Crack Growth To Optimize Drillstring Reliability, in: SPE/IADC Drilling Conference, 22-25 February 1993, Amsterdam, Netherlands, Society of Petroleum Engineers, ISBN 9781555634940, 1993. 
[7] G-theta procedure of CASTEM EF-code on http://www-cast3m.cea.fr/, ????

[8] P. Destuynder, M. Djaoua, S. Lescure, Quelques remarques sur la mécanique de la rupture élastique, Journal de Mécanique Théorique et Appliqué 2 (1983) 113-135.

[9] eXtended Finite Element Method, documentation de Reference de Code Aster no. R7.02.12, ????

[10] A. Shahani, S. Habibi, Stress intensity factors in a hollow cylinder containing a circumferential semielliptical crack subjected to combined loading, International Journal of Fatigue 29 (1) (2007) 128 140, ISSN 0142-1123.

[11] A. Sikal, J. Boulet, S. Menand, H. Sellami, Drillpipe Stress Distribution and Cumulative Fatigue Analysis in Complex Well Drilling: New Approach in Fatigue Optimization, in: SPE Annual Technical Conference and Exhibition, 21-24 September 2008, Denver, Colorado, USA, Society of Petroleum Engineers, ISBN 9781555631475, 2008. 